SIGUIENDO LA PISTA

\title{
Análisis de características diferenciales entre antocianinas y betacianinas en extractos de plantas mediante pruebas de color
}

\author{
Natalia Martínez Reyes
}

Estudiante de $4^{\circ}$ curso de Biotecnología (curso 2017-2018). Facultad de CC. Biologícas y Ambientales. Universidad de León.

nmartro5@estudiantes.unileon.es

Las antocianinas y las betacianinas son pigmentos rojos y violetas que, además de dar color a las plantas, poseen una importante función antioxidante, y cada vez más aplicaciones en el ámbito alimentario, médico y bioquímico. Estos pigmentos comparten ciertas similitudes, pero también presentan diferencias útiles a la hora de emplearlos en distintas aplicaciones, o de caracterizar plantas. El objetivo de este estudio es realizar pruebas de color sobre extractos crudos que permitan diferenciar entre antocianinas y betacianinas. Se ha observado que las antocianinas cambian su color en función del $\mathrm{pH}$, mientras que las betacianinas vagamente varían su color y se degradan en $\mathrm{pH}$ alcalino. Un tratamiento corto a $100^{\circ} \mathrm{C}$ con $\mathrm{HCl}$ también puede degradar las betacianinas, pero no las antocianinas. En metanol ácido, las antocianinas muestran máximos de absorción en el espectro visible más bajos, debido a su viraje hacia tonos rojos. Por último, en cromatografía en papel, y utilizando butanol:acético:agua como fase móvil, las antocianinas pueden separarse y caracterizarse, mientras que las betacianinas apenas migran, pero pueden separarse de las betaxantinas.

Palabras clave: antocianidinas, betalaínas, cromatografía BAW, pH, pigmentos.

\section{Introducción}

Las antocianinas y las betacianinas son los pigmentos más importantes que contribuyen al color de las flores desde el rojo hasta el violeta. Estos pigmentos pueden acumularse también en hojas, frutos, raíces y otros tejidos de las plantas, y se encuentran principalmente en la epidermis. Cumplen funciones de atracción de animales polinizadores y dispersores de frutos, y protegen frente al daño por radiación ultravioleta al DNA y los fotosistemas, gracias a sus propiedades antioxidantes(Horbowicz et al., 2008).

Tanto los atractivos colores, como las propiedades antioxidantes de estos pigmentos han sido aprovechados por los humanos, desde el disfrute de las flores 
y los frutos, hasta su utilización como pigmentos purificados para una variedad de aplicaciones: colorantes alimentarios, suplementos de antioxidantes, fluoróforos y marcadores biológicos en bioquímica. Como colorantes, poseen propiedades diferenciales útiles para optimizar su utilización, por ejemplo, las betacianinas son más solubles en agua que las antocianinas, pero son menos resistentes al calor que las segundas(Polturak y Aharoni, 2018).

En cuanto a su distribución en la naturaleza, existe un fenómeno de exclusión mutua entre antocianinas y betalaínas, el grupo al que pertenecen las betacianinas. Mientras que las antocianinas están presentes casi globalmente en el reino vegetal, las betacianinas solo se han observado en familias del orden Caryophyllales, en las cuales no se han detectado antocianinas (Brockington et al., 2011).

Las antocianinas son flavonoides, y muestran una paleta amplia de colores, desde el anaranjado hasta el azul. Su estructura básica se compone de un anillo benzopirano unido a un segundo anillo aromático llamado B (C6-C3-C6), cuyo conjunto constituye la antocianidina o aglicona (cromóforo) (Fig. 1). El color depende principalmente del número de grupos hidroxilo en el anillo B, proporcional al color azulado, mientras que las O-metilaciones lo modifican hacia apariencia rojiza (Delgado-Vargas et al., 2000). Esta aglicona se encuentra Oglicosidada comúnmente en las posiciones $\mathrm{C}_{3}, \mathrm{C}_{5}$ y C7, y, a su vez, estos azúcares pueden estar acilados con grupos aromáticos y alifáticos(Tanaka et al., 2008).
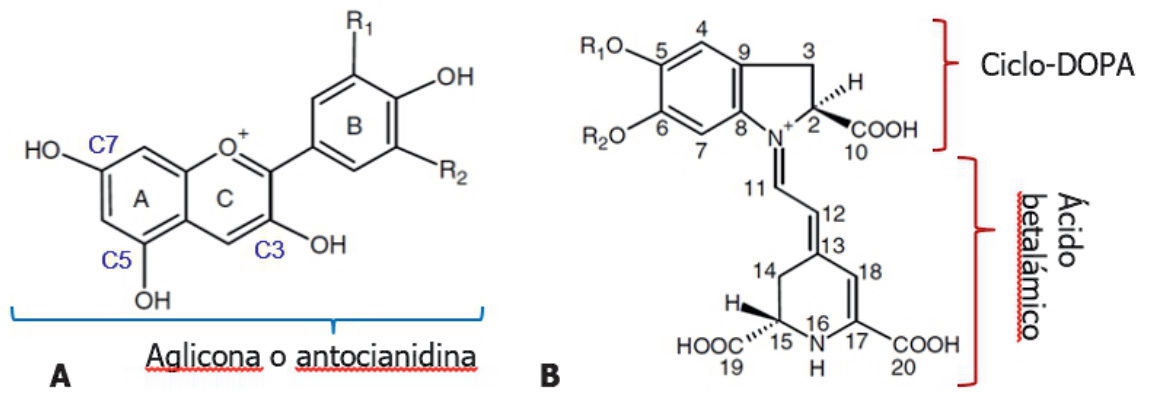

Figura 1. Estructura básica de las antocianidinas (A) y betacianinas (B). Modificado de Khan y Giridhar (2015).

El color de las antocianinas también depende del medio en que se encuentren: el pH causa cambios en la estructura de las antocianidinas con gran impacto en el color (Fig. 2), y la asociación con otros compuestos sin color (copigmentos), e iones metálicos $\left(\mathrm{Fe}^{3^{+}}, \mathrm{Al}^{3^{+}}\right)$modifica el color y la estabilidad (Tanaka et al., 2008). 




Figura 2. Representación de los cambios en la estructura y color de una antocianina en función del $\mathrm{pH}$. Modificado de Welch et al. (2009).

Las betalaínas son pigmentos ricos en nitrógeno derivados del ácido betalámico, procedente de la tirosina. Existen dos categorías de estos pigmentos: betacianinas (entre rojo y violeta) y betaxantinas (amarillas). En las primeras, el ácido betalámico se condensa con ciclo-DOPA, y en las segundas, con distintos aminoácidos. Ambos grupos deben su diversidad a las distintas modificaciones, glicosilaciones y acilaciones, en sus grupos hidroxilo, R1 y R2 en la Figura 1 (Khan y Giridhar, 2015). Las betaxantinas, además, presentan fluorescencia (García Carmona et al., 2011).

Los colores de las antocianinas y las betacianinas en condiciones naturales pueden ser similares, pero sus propiedades físico-químicas no. El objetivo de este trabajo es estudiar estas diferencias. Para ello, se realizaron pruebas sencillas de color y se caracterizaron los pigmentos en extractos crudos de remolacha y de ocho flores de colores morados y rosas, a los que contribuyen principalmente antocianinas y betacianinas. Estas pruebas fueron: comportamiento en $\mathrm{pH}$ ácido y alcalino, resistencia a tratamiento con ácido en caliente, espectro de absorbancia en el rango visible y cromatografía en papel.

\section{Materiales y métodos}

Extracción de los pigmentos con metanol acidificado

Tras la anotación previa de los colores de las muestras originales, se prepararon extractos metanólicos de raíz de remolacha roja (Beta vulgaris) y de flores de las siguientes especies: pensamiento (Viola $\times$ wittrockiana), dalia (Dhalia sp.), cactus de Navidad (Zygocactus truncatus), rosa (Rosa sp.), violeta africana 
(Saintpaulia ionantha), flor del día (Mirabilis jalapa), geranio (Pelargonium sp.) y cristalina (Impatiens balsamina). Para ello, se homogenizaron las muestras en un mortero con metanol al 80\% (v/v) que contenía $\mathrm{HCl}$ al 1\% (v/v), utilizando el mínimo volumen posible. Tras la maceración, los homogeneizados se filtraron a través de papel de filtro con ayuda de un embudo de filtración y una bomba de vacío, obteniendo el extracto final. El color de dicho extracto se volvió a anotar.

Modificación del color en medio básico y estabilidad del color en medio ácido caliente

De cada extracto, se tomó una pequeña alícuota en un tubo de ensayo, diluyéndola con el disolvente de extracción en los casos necesarios. Para comprobar la modificación del color en medio básico, se añadieron unas gotas de $\mathrm{NaOH}$ 2M, se agitó la disolución, y se anotó el color. Para comprobar la estabilidad del color en medio ácido caliente, se añadieron unas gotas de $\mathrm{HCl} 2 \mathrm{M}$ a otra alícuota diluida, y se calentaron los tubos a $100^{\circ} \mathrm{C}$ durante 5 min en un baño de agua hirviendo. Posteriormente, se anotó el color.

Determinación del espectro de absorción en el rango visible de los extractos

Los extractos se diluyeron con metanol ácido (dilución 1:4) y se realizó un barrido desde 400 hasta $600 \mathrm{~nm}$ en un espectrofotómetro PharmaSpec UV-1700 (Shimadzu).

\section{Cromatografía con butanol:acético:agua (BAW)}

Se realizó por duplicado una cromatografía ascendente sobre papel Whatman $\mathrm{n}^{0} 1$ (20cm x 20cm). Sobre el papel se aplicaron por triplicado $15 \mu \mathrm{lde}$ cada extracto y de cianidina, secando entre cada aplicación con un secador. Se preparó la cámara cromatográfica con la fase móvil (n-butanol:ácido acético:agua, 8:2:1 vol:vol) y se introdujo el papel en forma cilíndrica, se cerró y se precintó con cinta de carrocero. Se dejó correr hasta que el frente se aproximó al borde superior del papel. Entonces, se extrajo el cromatograma y se dejó secar. Se calcularon los valores de $\mathrm{Rf}$ dividiendo la distancia que había migrado la mancha por la del frente.

\section{Resultados y discusión}

Color de las muestras previo a la extracción

Los colores de las muestras, antes de ser procesadas, oscilaron entre rosa, morado y granate (Tabla 1). Esta observación a simple vista no permite distin- 
guir entre antocianinas y betacianinas, ya que estos colores se solapan en la paleta de ambos pigmentos.

Teniendo en cuenta la exclusión mutua entre antocianinas y betalaínas, debe notarse que se estudiaron tres representantes del orden Caryophyllales: remolacha, cactus de Navidad y flor del día, candidatos a presentar betacianinas.

Cambio del color de los extractos en metanol ácido

Para la extracción, se utilizó metanol acidificado con $\mathrm{HCl}$, dado que un medio ácido favorece la estabilidad de las antocianinas. Precisamente, la acidificación del solvente es la causa de la variación del color nativo de las muestras en los extractos (Tabla 1). La mayoría de los extractos en medio ácido viraron al rojo, en general un rojo brillante. La remolacha y el cactus de Navidad cambiaron de un color purpúreo a granate, y la flor del día pasó de presentar un color granate a uno purpúreo.

Tabla 1. Colores de las muestras originales, así como de los extractos al ser obtenidos mediante metanol acidificado y al ser tratados con $\mathrm{NaOH} 2 \mathrm{M}$. Se ilustra el cambio de color de las muestras simulando una escala de $\mathrm{pH}$.

\begin{tabular}{|c|c|c|c|}
\hline Nombre común & $\begin{array}{c}\text { Color del } \\
\text { extracto }\end{array}$ & Color de la muestra & Color en NaOH \\
\hline Pensamiento & Rojo intenso & Morado intenso & Verde botella \\
\hline Violeta africana & Rojo magenta & Violeta intenso & Amarillo \\
\hline Rosa & Rojo piruleta & Púrpura & Verde botella \\
\hline Geranio & Rojo claro & Morado rosáceo & Amarillo-naranja \\
\hline Dalia & Rojo piruleta & Rosa & Verde \\
\hline Cristalina & Rojo & Rosa intenso & Verde oscuro \\
\hline Remolacha roja & Rojo vino & Morado intenso & Amarillo \\
\hline Cactus de Navidad & Rojo granate & Granate & Amarillo claro \\
\hline Flor del día & Morado & Granate & Amarillo \\
\hline
\end{tabular}

En las antocianinas, el viraje de color causado por descenso de $\mathrm{pH}$ se debe al cambio de la estructura de la molécula, que se muestra como catión flavilio (ver Fig. 2), con colores entre el rojo y el naranja (Welch et al., 2009). Este fenómeno explica el color rojo brillante que muestran los extractos de pensamiento, dalia, rosa, geranio y cristalina. El extracto de violeta africana no es claramente rojo, pero el cambio de color tiende hacia este tono.

El color de las betacianinas no cambia tanto con el descenso de $\mathrm{pH}$, aunque puede variar ligeramente (Khan y Giridhar, 2015). En los tres miembros del orden Caryophyllales, se observa que el cambio en el color tras la extracción no 
es tan acusado como en el resto de extractos y, además, ninguno se asemeja al rojo brillante, sino que oscilan entre el granate y el morado.

\section{Modificación del color en medio básico}

$\mathrm{Al}$ añadir unas gotas de $\mathrm{NaOH} 2 \mathrm{M}$ a una pequeña alícuota de los extractos, la alcalinidad aumenta fuertemente y los pigmentos viran de color o se degradan (Tabla 1).

Los tres extractos de betacianinas: remolacha, cactus de Navidad y flor del día, se tornaron amarillos, color que no muestran los pigmentos en su estado nativo. Puesto que no se han descrito formas químicas intermedias de las betacianinas que expliquen este color, pero sí se ha indicado que su degradación puede dar lugar a compuestos amarillos, como es el ácido betalámico(Khan y Giridhar, 2015), se deduce que el cambio del color de los extractos alcalinizados es consecuencia de la degradación de las betacianinas.

La Fig. 3 muestra el cambio de color del extracto de violeta africana. Al principio se añadió una gota, observándose una coloración verde que se desvaneció al agitar, y tras añadir varias gotas (nótese el aumento de volumen) adquirió coloración amarilla. Este cambio de color no tiene por qué indicar necesariamente la degradación de las antocianinas (Welch et al., 2008), al contrario de lo que sucedía con las betacianinas. En la Fig. 3 también se puede observar el cambio de color hacia el verde, en el extracto de rosa, al añadir una gota de $\mathrm{NaOH} 2 \mathrm{M}$.

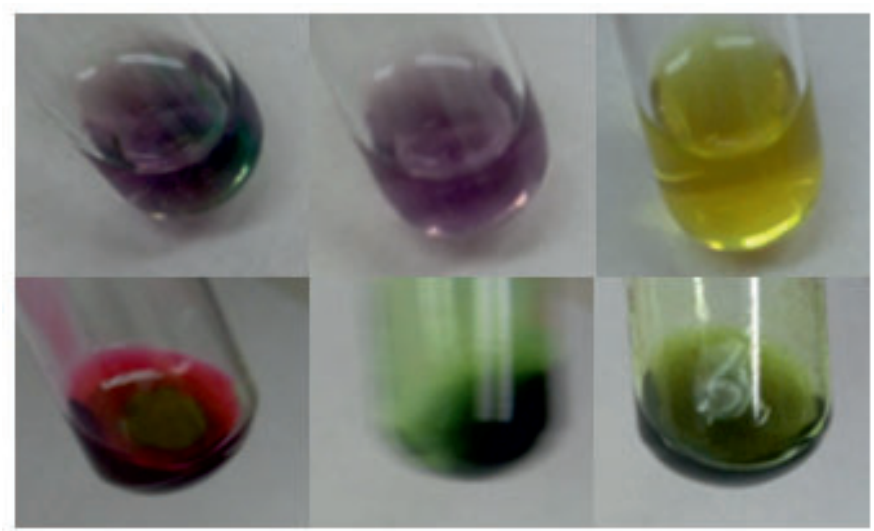

Figura 3. Viraje del color tras añadir unas gotas de $\mathrm{NaOH}$ en el extracto de violeta africana (superior) y de rosa (inferior).

Estabilidad del color en medioácido caliente

Como se observa en la Tabla 2, las antocianinas se mantuvieron estables en el medio ácido tras el tratamiento térmico a $100^{\circ} \mathrm{C}$ durante $5 \mathrm{~min}$, mostrando variaciones ligeras en el tono rojo. En cuanto a las betacianinas, los pigmentos de la remolacha mantuvieron cierta estabilidad, mientras que la coloración de los 
extractos de flor del día y cactus de Navidad desapareció, dejando colores amarillentos.

La estabilidad tras este tipo de tratamientos es un aspecto diferencial de relevancia entre las antocianinas y las betalaínas: las betalaínas son altamente inestables a temperaturas elevadas (Delgado-Vargas et al., 2000). En el caso de la remolacha roja, la despigmentación parcial puede significar que la concentración de pigmentos era muy elevada, y en el corto tiempo del tratamiento, parte conservaron su estructura.

Tabla 2. Resultados del tratamiento con ácido caliente sobre los extractos.

\begin{tabular}{|c|c|c|}
\hline $\begin{array}{c}\text { Nombre común } \\
\text { Pensamiento }\end{array}$ & $\begin{array}{c}\text { Color del extracto } \\
\text { Rojo intenso }\end{array}$ & $\begin{array}{c}\text { Color en } \mathbf{H C l ~} \mathbf{~ 1 0 0}^{\circ} \mathbf{C} \\
\text { Rojo piruleta }\end{array}$ \\
\hline Violeta africana & Rojo magenta & Rojo magenta \\
\hline Rosa & Rojo piruleta & Rojo piruleta \\
\hline Geranio & Rojo claro & Rojo piruleta \\
\hline Dalia & Rojo piruleta & Rojo más claro \\
\hline Cristalina & Rojo & Rojo cereza \\
\hline Remolacha roja & Rojo vino & Rojo \\
\hline Cactus de Navidad & Rojo granate & Beige amarillo \\
\hline Flor del día & Morado & Sepia \\
\hline
\end{tabular}

Determinación del espectro de absorción en el rango visible

Los espectros de absorción de las betacianinas para longitudes de onda $(\lambda)$ entre 400 y $600 \mathrm{~nm}$ presentaron distintos perfiles, mientras que los de las antocianinas fueron muy similares (Fig. 4). El aspecto global a destacar es que los picos de absorción de los extractos de betacianinas se situaron por encima de $536 \mathrm{~nm}$, mientras que los de antocianinas se encontraron en un rango más bajo, entre 532 y $502 \mathrm{~nm}$.

El solvente, metanol ácido, ayuda a marcar la diferencia, ya que las antocianinas se vuelven más rojas, y por lo tanto, su máximo de absorción se desplaza a $\lambda$ menores. Este aspecto es útil para diferenciarlas, ya que se cumple de modo general(Khan y Giridhar, 2015). 

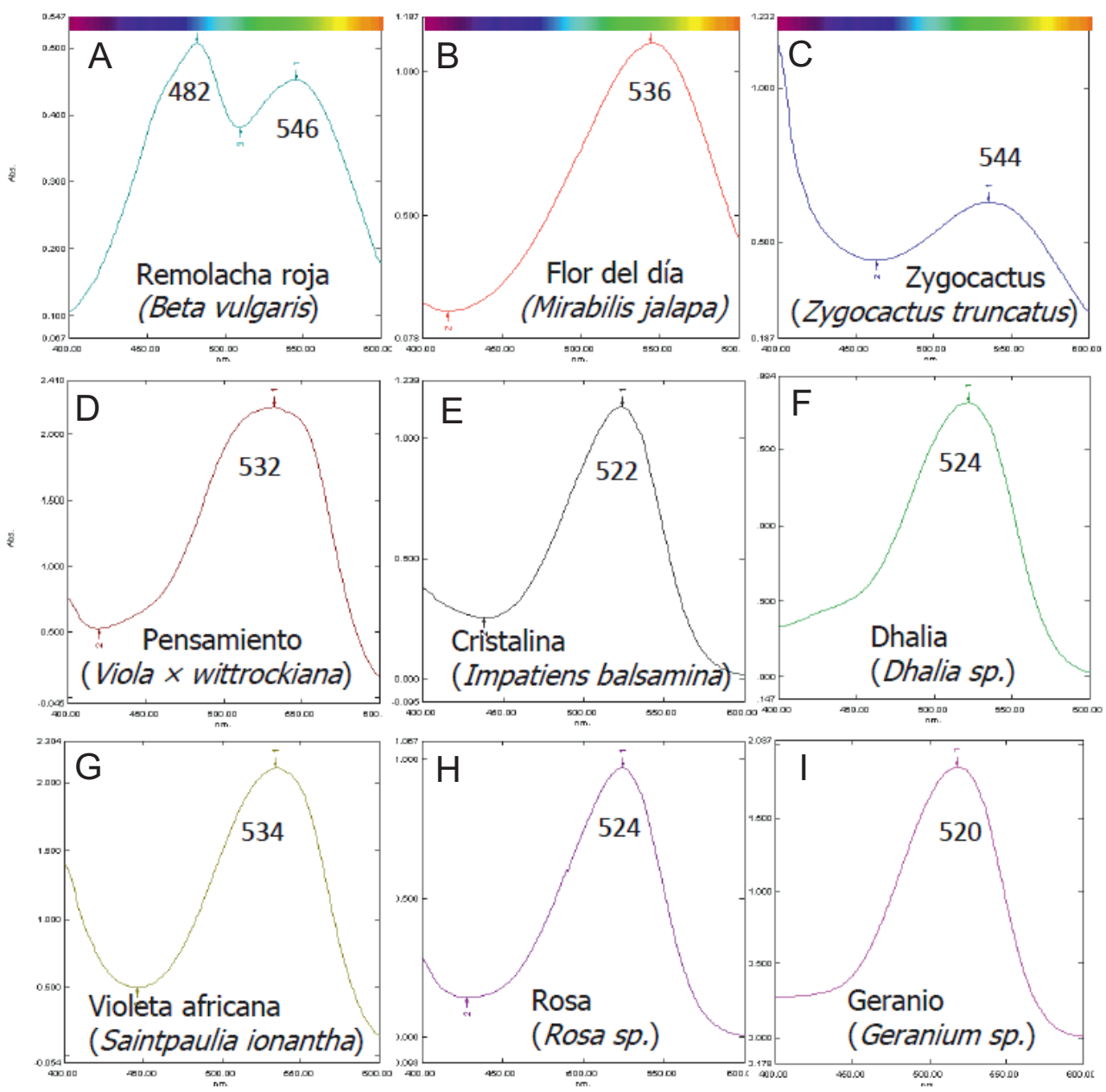

Figura 4. Espectros de absorción de luz de los extractos de betacianinas $(\mathrm{A}-\mathrm{C})$ y antocianinas (D-I) en metanol-HCl para $\lambda$ entre 400 y $600 \mathrm{~nm}$. Se indica el valor de $\lambda$ en la cual se alcanza el máximo de absorción.

En este experimento, destaca el solapamiento de los espectros de flor del día y violeta. Esto indica que el color del extracto de violeta tiende a ser morado, a pesar de las condiciones ácidas, lo que puede deberse a alguna modificación que aporta estabilidad y color azul, como un grupo acilo.

Cromatografía en papel de antocianinas y betacianinas

El valor de Rf en este tipo de cromatografía es indicativo para diferenciar betacianinas de antocianinas, ya que la migración de las primeras es escasa, mucho menor que la de las antocianinas en general (Delgado-Vargas et al., 2000). Como puede observarse en la Fig. 5 y en las Tablas 3 y 4, el Rf de las betalaínas se situó por debajo de 0,26 , mientras que todas las antocianinas mostraron valores superiores. En el cromatograma aparecen otros compuestos del extracto crudo que pueden co-migrar o no con los pigmentos en estudio y que pueden apreciarse bajo radiación ultravioleta. 


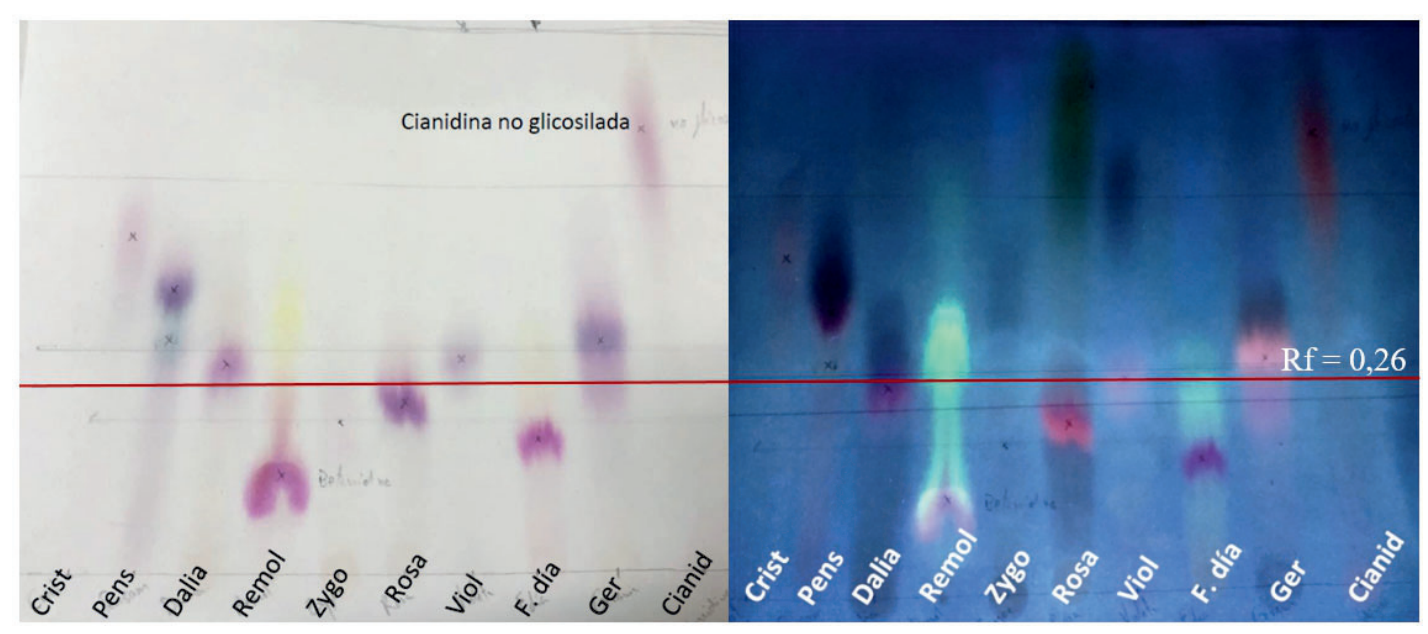

Figura 5. Cromatograma en papel BAW (8:2:1) de los extractos en estudio (dcha.), y visualización bajo radiación ultravioleta de 350 $\mathrm{nm}$ (izq.). Avance del frente: $13,5 \mathrm{~cm}$. Se marca, como referencia, el valor de Rf de 0,26.

La Tabla 3 muestra la aproximación de la identidad de las antocianinas aisladas tomando como referencia los valores de Rf de Harborne (1973). La migración de las antocianinas en BAW es inversamente proporcional al número de glicosilaciones y, a su vez, es característica para cada antocianidina. Así, la cianidina (no glicosilada) es la que más migra. Además, si se encuentran aciladas, migran más, son más estables y más azules (Horbowicz et al., 2008), por lo que la violeta africana, dada su estabilidad en $\mathrm{NaOH}$, y su color fuerte, parece poseer malvidina 3-acetilrutinósido-5-glucósido, como se ha visto en el estudio de Tatsuzawa y Hosokawa (2016).

Tabla 3. Resultados de la cromatografía en BAW y de la espectroscopía, y antocianinas probables.

\begin{tabular}{|c|c|c|c|c|}
\hline $\begin{array}{c}\text { Nombre } \\
\text { común }\end{array}$ & $\begin{array}{c}\text { Color de la } \\
\text { muestra }\end{array}$ & $\begin{array}{c}\text { Rf en } \\
\text { BAW }\end{array}$ & $\begin{array}{c}\text { A máx } \\
\text { MetoH- } \\
\text { HCl (nm) }\end{array}$ & Antocianina \\
\hline Pensamiento & $\begin{array}{c}\text { Morado } \\
\text { intenso }\end{array}$ & 0,38 & 532 & $\begin{array}{c}\text { Delfinidina 3-glucósido (azul) } \\
\text { Petunidina 3-glucósido }\end{array}$ \\
\hline $\begin{array}{c}\text { Violeta } \\
\text { africana }\end{array}$ & $\begin{array}{c}\text { Violeta } \\
\text { intenso }\end{array}$ & 0,37 & 534 & $\begin{array}{c}\text { Malvidina 3-acetilrutinósido 5- } \\
\text { glucósido }\end{array}$ \\
\hline Rosa & Púrpura & 0,28 & 524 & Cianidina 3,5-triglucósido \\
\hline Geranio & Rosáceo & 0,40 & 520 & Pelargonidina 3,5-diglucósido \\
\hline Dalia & Rosa & 0,35 & 524 & Cianidina 3,5-diglucósido \\
\hline Cristalina & Rosa intenso & 0,57 & 522 & Cianidina 3-glucósido \\
\hline Cianidina & - & 0,80 & - & Cianidina \\
\hline
\end{tabular}


Las betacianinas poseen modificaciones de la estructura principal más heterogéneas, y su color es poco variable (Khan y Giridhar, 2015), por lo que los análisis realizados no son los adecuados para identificarlas. Aun así, es posible distinguir dos tipos de betalaínas en la cromatografía: betacianinas y betaxantinas (Fig. 5). Las betacianinas aparecen como una mancha morada. En remolacha, la mancha no está bien definida, por lo que probablemente haya más de un tipo de betacianina, betaninas, la mayoría; en la imagen bajo UV, se observa un rastro de betaxantina fluorescente (miraxantinas y vulgaxantinas, unidas a distintos aminoácidos). En el cactus de Navidad, aparece una betacianina rosácea. Mirabilis jalapa, la flor del día, muestra dos tipos de pigmentos, una betacianina, y un rastro de betaxantina, probablemente miraxantinas (Khan y Giridhar, 2015; Delgado-Vargas et al., 2000).

Tabla 4. Resultados de la cromatografía en BAW y de la espectroscopía de las muestras de betacianinas.

\begin{tabular}{|c|c|c|c|}
\hline Nombre común & $\begin{array}{c}\text { Color de la } \\
\text { muestra }\end{array}$ & Rf en BAW & $\begin{array}{c}\boldsymbol{\lambda} \text { máx (MetoH-HCl) } \\
\text { (nm) }\end{array}$ \\
\hline Remolacha roja & Morado intenso & 0,16 & 546 y 482 \\
\hline Cactus de Navidad & Granate & 0,25 & 536 \\
\hline Flor del día & Granate & 0,22 & 544 \\
\hline
\end{tabular}

En vista de estos resultados, puede concluirse que las pruebas empleadas son eficaces para distinguir entre antocianinas y betacianinas, y que permiten la caracterización aproximada de antocianinas, aunque no son completamente adecuadas para la de betacianinas. Los cambios de color en función del pH permiten una distinción rápida, pero, en caso de que los colores de las antocianinas sean oscuros, el pH ácido no supone un viraje al rojo muy marcado. De la misma manera, si el color no cambia en la extracción, los picos de máxima absorbancia tampoco marcarán la diferencia. Por el contrario, la estabilidad, tanto en $\mathrm{pH}$ alcalino, como en tratamiento ácido-térmico, ha resultado un aspecto diferencial capaz de disipar estas dudas de color: las betacianinas son inestables, y se degradan en estos tratamientos. La cromatografía en papel con fase móvil BAW permite separar antocianinas de betacianinas eficazmente, $y$, además, permite la separación de los distintos tipos de antocianinas, para su caracterización.

\section{Bibliografía}

Brockington, S.F., Walker, R.H., Glover, B.J., Soltis, P.S., y Soltis, D.E. (2011). Complex pigment evolution in the Caryophyllales. New Phytologist 190, 854-864. 
Delgado-Vargas, F., Jiménez, A.R., y Paredes-López, O. (2000). Natural pigments: Carotenoids, anthocyanins, and betalains Characteristics, biosynthesis, processing, and stability. Critical Reviews in Food Science and Nutrition 40,173-289.

García Carmona, F., Gandía Herrero, F., y Escribano, J. (2011). Flores fluorescentes. Investigación y Ciencia 415, 50-57.

Harborne, J.B. (1973). Phenolic Compounds. En Phytochemical Methods (ed. Chapman and Hall) pp. 33-88, Londres, Reino Unido.

Horbowicz, M., Grzesiuk, A., Dębski, H., y Kosson, R. (2008). Anthocyanins of fruits and vegetables - Their occurrence, analysis and role in human. Vegetable Crops Research Bulletin 68, 5-22.

Khan, M.I., y Giridhar, P. (2015). Plant betalains: Chemistry and biochemistry. Phytochemistry 117, 267-295.

Polturak, G., y Aharoni, A. (2018). «La Vie en Rose»: Biosynthesis, sources and applications of betalain pigments. Molecular Plant 11, 7-22.

Tanaka, Y., Sasaki, N., y Ohmiya, A. (2008). Biosynthesis of plant pigments: Anthocyanins, betalains and carotenoids. Plant Journal 54, 733-749.

Tatsuzawa, F., y Hosokawa, M. (2016). Flower colors and their anthocyanins in Saintpaulia cultivars (Gesneriaceae). The Horticulture Journal 85, 6369.

Welch, C.R., Wu, Q., y Simon, J.E. (2008). Recent advances in anthocyanin analysis and characterization. Current Analytical Chemistry 4, 75-101. 